\title{
Technician education and training: a plan for systemic change
}

\section{Daniel Hull}

Daniel M. Hull, "Technician education and training: a plan for systemic change," Proc. SPIE 4588, Seventh International Conference on Education and Training in Optics and Photonics, (28 May 2002); doi: 10.1117/12.468683

SPIE Event: Education and Training in Optics and Photonics 2001, 2001, Singapore, Singapore 
Invited Paper

\title{
Technician Education and Training: \\ A Plan for Systemic Change
}

\author{
Daniel M. Hull \\ President and Chief Executive Officer \\ CORD \\ 601 Lake Air Drive, Waco, Texas, USA
}

\begin{abstract}
World-Class Technicians in emerging and rapidly changing fields such as Photonics require interdisciplinary technical skills, a strong, practical academic/technical core, highly interactive people skills, and the ability to think critically and solve open-ended problems. An improved curriculum and delivery system is required that spans both secondary and postsecondary experiences, along with employer-provided internships. A strong, useful math/science foundation must be provided using contextual teaching and learning strategies.

A Photonics Technician education program will be presented that demonstrates the new curriculum model described above. The Photonics Technician Program has been recently designed and developed in the USA under an NSF grant. It is being tested in community and technical colleges. The technical aspects of the program are based on a Laser/ElectroOptics Technology curriculum, developed by CORD, that has been successfully used by twenty-five colleges as well as hundreds of businesses in the USA over the last twenty-five years.
\end{abstract}

\section{Keyword list}

- Careers

- Contextual teaching and learning

- Curriculum

- Engineering

- Learning
- Photonics

- Postsecondary

- Secondary

- Teaching

- Technicians

Photonics is an example of many modern technologies emerging in the last fifteen years that require a new educational system for career preparation. Some characteristics of the emerging technologies are

- Systems orientation

- Strong foundation in useful math and science

- Interdisciplinary

- Rapidly changing

This new educational system is evolving in the United States and in several other countries throughout the world. It addresses the employment standards that most organizations will require to ensure flexibility, performance, and continuity for economic competitiveness and employee growth and advancement.

The term "new system"- as used here-includes the curriculum, teaching strategies, guidelines, and policies that will enable educational institutions to provide appropriate guidance, educational, and work experiences that will help our youth prepare for careers - not jobs.

\section{WHY IS THE SYSTEM CHANGING?}

For the last two decades we have recognized that the vocational education system that served our country so well for two-thirds of the last century is no longer able to meet the needs of the vast majority of our young people in secondary schools and colleges. Traditional vocational education was created to teach manual skills for the industrial and 
agricultural sectors of our economy. Today, these sectors represent a diminishing part of the economy and can, in fact, be staffed increasingly by smart machines. In the past, the original goal of secondary vocational education was to provide "entry-level skills" for workers in agriculture, health, business, service, trade, and manufacturing enterprises. Unfortunately, many vocational programs in our secondary schools have been used as dumping grounds for academically poor achievers and disinterested and/or "problem" students.

Community and technical colleges do not usually refer to their offerings as "vocational" - choosing instead descriptors such as "career" or "technical education." And these tech ed programs are mostly filled with adults (average age 29 years), many of whom require remediation in math, science, and communication and who generally take one or two courses (part time) to help them get new jobs or to refresh their skills. Approximately 64 percent of the 5.4 million credit students enrolled in U.S. community and technical colleges are there only part time, and only 482,000 of the 10.4 million receive associate degrees each year. ${ }^{1}$ In 1995,45 percent of the students enrolled in public two-year institutions were enrolled in one or more developmental courses. ${ }^{2}$

With our rapid transformation to an information-based economy, employers are placing less value on short-term skills and more value on one's ability to work as part of a team; to use technology effectively; and to synthesize, integrate, apply, and build on basic knowledge. ${ }^{3}$ The issue is not "skills versus knowledge" for some students. Rather, it is the appropriate combination of skills and knowledge for all students.

An unfortunate result of the knowledge explosion we have witnessed in the last forty years has been that information and skills have been segregated into discrete disciplines in order to manage them more effectively for student learning (i.e., math is separated from science is separated from English is separated from history). We have attempted to create huge "pipes" of isolated disciplines in the minds of students and have assumed that they will assimilate and integrate this information successfully to solve real problems in life and work. Cognitive learning theories verify experience that only a few students can learn efficiently via "pipes of information," and even fewer can apply what they've learned to experience and practice. This distressing result is not the problem of just traditional vocational education, it is endemic to all areas of education. In other words, many of those who regularly dispense abstract and academic concepts do not use effective teaching styles for applied or concrete learners (typically vocational students), and they often do not make academics useful to even the more abstract learners. Recent educational reforms, such as Tech Prep, have shown that concrete or applied learners can master rigorous academic courses if they are "taught in context" and that the context of work (careers) is useful for maintaining students' interest and enhancing the learning process.

In the closing decade of the last century, U.S. educators and their business and industry partners - through Tech Prepforged bold initiatives in an attempt to improve the system:

- They have articulated course offerings between secondary and postsecondary institutions to eliminate duplication.

- They have pioneered efforts to improve student achievement through applied or contextual academics.

- They have established standards-based curricula and assessment strategies.

- They have cooperated to create work-based learning environments for students to experience careers and add "context" to their class and lab work.

- They have successfully explored the structure of career academies to create schools within schools, or magnet schools.

Similar changes are occurring in Western Europe, Brazil, Malaysia, and Chile, to name a few.

But major, fundamental changes to curricula, delivery systems, and teaching styles have not occurred systematically or to scale across states. Secondary vocational educational programs, in an attempt to keep pace with the new concepts and skills required by emerging technologies, have introduced some useful changes, but they are mostly building on curricula and structures they've used in the past. In many instances, they're still conducting job training for poor

\footnotetext{
${ }^{1}$ American Association of Community Colleges.

${ }^{2}$ U.S. Department of Education, National Center for Education Statistics, "Remedial Education at Higher Education Institutions in Fall 1995."

${ }^{3}$ Secretary's Commission on Achieving Necessary Skills (SCANS), 1993.
} 
academic achievers and problem students - even though job training is not the education our young people need to prepare them for rewarding, lifetime careers.

In addition, at community and technical colleges, technical education is not attracting large numbers of recent secondary graduates - full-time students with good academic achievement. Those few whom technical education does attract are being combined in classes with older adults who can afford to invest in only short-term job training experiences.

Because of their limitations of time for further education and training, most older adults probably do need to focus on job training with infusion of some basic academics. Community and technical colleges have been designing their curriculum content and level for this population because it represents the largest group the colleges serve in technical education. But these short-term offerings cannot constitute the postsecondary component of the new system of education for careers that is proposed here because these offerings cannot attract or serve recent secondary graduates who are academically strong, who are focused on career objectives, and who have completed technical core offerings prior to secondary graduation. Resources that are allocated to support the changes to the new system must be proportionally larger for postsecondary institutions if this new focus is to be achieved.

\section{THE NEW SYSTEM: A COHERENT DESIGN USING THE PIECES THAT WORK}

The target population for the new system is our young people in grades nine through fourteen (secondary and community/technical college) who are concrete learners - those who learn best in context. These learners typically represent 60 percent of the student body and are sometimes referred to as the "neglected majority" or "forgotten half." However, the new system will serve any or all capable students because it will teach to broad academic standards. Its secondary graduates will be qualified equally for university admission, for community and technical colleges, or for employment, because they have demonstrated mastery of the basic academic disciplines. Because of this, the new system will be viewed by counselors, parents, and those in higher education as a preferred educational experience with a firm academic foundation for all students.

The specifications for the new system are standards: academic standards, skill standards, and employability (soft skill) standards. Each state is currently developing such standards. If their work is coordinated and follows a consistent format, the differences in these standards from state to state should not be great. Although the new system focuses on young people over a six-year grade span, it should be active and relevant for the career life of the individual. It will enable students and workers to exit and reenter many times, according to the peculiar needs of the individuals and according to changing requirements of the career paths. The new system presumes a new definition of "job-entry skills" that requires a solid education - including useful academics, a career interest and focus, critical thinking, ethics, and interpersonal skills. The new system is organized into broad career areas, such as health, information technology, engineering, and business. And, within a career area, the new system allows an individual to pursue a wide latitude of occupations. The new system is not equipment based; it is knowledge and technology based.

The new system can be characterized by eight critical elements, which are described as follows:

\section{Career Clusters}

More than at any time in history, our young people are searching for meaning in school. They're asking, "Why do I have to learn this? How will I use it?" A career focus in education helps these young people relate what they are learning to their future; it provides motivation for them to work for higher levels of achievement.

Career clusters, organized around today's rewarding occupations, provide a structure by which schools can organize guidance and instruction for students according to their interests and career goals. Clusters are a tool that counselors and parents can use to assist every student entering secondary in developing a plan for entering college and employment. Used properly, career clusters keep students' options open, as opposed to locking them into a tracked system of job training. For us to achieve this structure, the criteria for grouping of careers into specific clusters should be made according to common knowledge and skills. 
In 1999, the U.S. Department of Education (ED) adopted the following system of sixteen career clusters:

Agriculture and Natural Resources

Arts, Audio and Video Technology, and

Communication

Business and Administrative Services

Construction

Education and Training Services

Financial Services

Health Science

Hospitality and Tourism

\author{
Human Services \\ Information Technology Services \\ Legal and Protective Services \\ Manufacturing \\ Public Administration and Government \\ Retail and Wholesale Sales and Services \\ Scientific Research, Engineering, and Technical \\ Services \\ Transportation, Distribution, and Logistics
}

Photonics falls into the "Scientific Research, Engineering, and Technical Services" cluster.

Although not perfect, this system can group most occupations according to common sets of knowledge and skills. This grouping will facilitate the design of the new curriculum, as we show later. A major update in this system is a clear recognition of Information Technology as an emerging cluster of careers. A few occupations within a cluster may require education and training in secondary only, but most will also require some level of postsecondary preparation.

\section{Academics Taught in Context}

The curriculum for the new system requires that all students master high levels of math, science, communication, and social studies and be able to articulate to any institution of higher education.

In the last fifteen years, text materials have been created in mathematics and science that incorporate contextual teaching and learning. But materials alone are not sufficient. Studies have shown that - along with good learning materials - contextual teaching can significantly improve student achievement, but only when teachers have been trained to use these strategies effectively. Most preservice programs in teacher education do not include contextual teaching. Hopefully, this will change, albeit slowly. The successful evolution of the new system will require a significant commitment to professional development for existing teachers.

As the need for higher-level academic and work skills increases, the challenge to help all students master these skills grows stronger. But the majority of students in our schools are unable to make connections between what they are learning and how that knowledge will be used. This disconnect occurs because of the way students process information and because traditional methods of classroom teaching do not increase their motivation for learning. Many students have difficulty understanding abstract academic concepts as they are commonly taught. This situation must be corrected because today's students desperately need to understand basic math, science, and communication concepts as they relate to the workplace and to the larger society in which they live and work.

Contextual learning is a proven concept that incorporates the most recent research in cognitive science. ${ }^{4}$ It is also a reaction to the behaviorist theories that have dominated American education for many decades. The contextual approach recognizes that learning is a complex and multifaceted process that goes far beyond drill-oriented, stimulus-and-response methodologies.

According to contextual learning theory, learning occurs best when students (learners) process new information or knowledge in such a way that it makes sense to them in their own frames of reference (their own inner worlds of memory, experience, and response). This approach to learning and teaching assumes that the mind naturally seeks

${ }^{4}$ CORD. Teaching Mathematics Contextually: The Cornerstone of Tech Prep. Waco, TX: CORD Communications, Inc., 1999.

CORD. Teaching Science Contextually: The Cornerstone of Tech Prep. Waco, TX: CORD Communications, Inc., 1999. Dale Parnell. Contextual Teaching Works! Waco, TX: CCI Publishing, 2000. 
meaning in context — that is, in relation to the person's current environment — and that it does so by searching for relationships that make sense and appear useful.

Building upon this understanding, contextual learning theory focuses on the multiple aspects of any learning environment, whether a classroom, a laboratory, a computer lab, a worksite, or a wheat field. It encourages educators to choose and/or design learning environments that incorporate as many different forms of experience as possible — social, cultural, physical, and psychological—in working toward the desired learning outcomes.

In such an environment, students discover meaningful relationships between abstract ideas and practical applications in the context of the real world; concepts are internalized through the process of discovering, reinforcing, and relating. For example, a physics class studying thermal conductivity might measure how the quality and amount of building insulation material affect the amount of energy required to keep the building heated or cooled. Or a biology or chemistry class might learn basic scientific concepts by studying the spread of AIDS or the ways in which farmers suffer from and contribute to environmental degradation.

Curricula and instruction based on this strategy are being structured to encourage five essential forms of learning:

Relating - Learning in the context of life experiences

Experiencing - Learning in the context of exploration, discovery, and invention

Applying - Learning in the context of how knowledge and information can be used

Cooperating - Learning in the context of sharing, responding, and communicating with others

Transferring - Learning in the context of existing knowledge — using and building on what we know

\section{New, Unified, Standards-Based Curricula}

A curriculum specifies "what," "how much," and "when" in the learning process (i.e., content, scope, and sequence). The curriculum is the "blueprint" upon which the entire new system should be based. Curriculum sequence will be organized around each career cluster. Content and scope will be based on state-established academic, skill, and employability (or soft) standards. Curricula for the new system incorporate all four years of secondary plus a variety of postsecondary options (one year, two years, four, or more, depending on the breadth and depth of content and possible certification requirements).

The new curriculum could be described as being strong in academics with a career focus, while keeping options open. Can all of this be done without placing students into a narrow track - especially when many are not yet ready to commit to their life ambitions? Yes, but only if the curriculum is structured to provide broad career skills matched with challenging academics in the early years of secondary school and is not made specific to a particular job until after secondary.

"Curriculum frameworks"- as outlined in Figure 1-center around foundation courses, technical core courses, and specialty courses, over a span of grades nine through sixteen. Such frameworks are being developed at a national level for each of the clusters defined above. The frameworks will then be used by local and state educators to create new curricula that are appropriate to the region or state being served.

Figure 1 shows in detail how the curriculum for each cluster could be structured. 


\begin{tabular}{|c|c|}
\hline \multicolumn{2}{|c|}{ A Conceptual Model for Design of New Curriculum Frameworks } \\
\hline & Technical Specialty \\
\hline \multirow[t]{2}{*}{$\begin{array}{c}\text { Grades } 15-16 \\
\text { and } \\
13-14 \\
\end{array}$} & $\begin{array}{l}\text { Advanced technical skills in occupational areas } \\
\text { Advanced academics } \\
\text { Internships and/or apprenticeships }\end{array}$ \\
\hline & Technical Core \\
\hline \multirow[t]{2}{*}{ Grades $11-12$} & $\begin{array}{l}\text { Technical skills within cluster } \\
\text { Advanced academics } \\
\text { Work-based learning }\end{array}$ \\
\hline & Foundation \\
\hline Grades 9-10 & $\begin{array}{l}\text { Academics in context } \\
\text { Career experiences } \\
\text { Basic employability skills }\end{array}$ \\
\hline
\end{tabular}

Figure 1. Curriculum frameworks for grades 9-16

In the secondary component of the curricula, the academic core for every cluster will include the same high-level, rigorous courses in math, science, English, social studies, and so on, but infused with applications and open-ended problems that relate to the chosen career cluster. In addition, the secondary curriculum should contain at least one major course each year (grades nine through twelve) that integrates the academic disciplines to support requirements of the skill standards within the career cluster.

The major courses in the ninth and tenth grades will be broad (including employability skills useful to all areas of work) but will allow students to experience and understand the nature of work in their chosen clusters. Based on their experience and understanding in these courses, some students may want to change their majors to other career clusters - and the curriculum will allow this without significant loss in required knowledge, skill, or credit.

In the last two years of secondary school (eleventh and twelfth grades) students will take major courses that are a part of the technical core of the career cluster. These courses are not "skills-only job training"; instead, they incorporate high levels of the academics that students are learning within the disciplines. A student may elect to take more than one course each term, and more advanced courses may be available at postsecondary institutions through dual-enrollment processes. All students in the eleventh and twelfth grades should also be required to participate in career-related internships with local employers, or service learning, as explained in the next section.

Students completing the secondary portion of the new curriculum will have attained all requirements for secondary graduation and entry to most postsecondary institutions. They will also be employable in entry-level occupations within their chosen career clusters. The postsecondary section of the new curriculum is a smooth, unified extension of the secondary level, building on the academic and technical core provided in secondary school. It will provide more specialization in occupational fields (such as health, business, management, manufacturing, information systems, engineering), leading to employment, certification, and/or professional recognition.

Successful implementation and student accomplishment in the new curriculum are dependent on entering students who have been well prepared in middle school. Thus, students entering secondary must be adequately prepared at the proper reading level and either have successfully completed algebra or be ready to enter algebra. They should also have been exposed to career opportunities and have developed some preference for their future careers. The new system places a strong demand on middle school reform.

\section{Work-Based Learning}

The historical (but unspoken) goal of education is that students leave one level of education prepared to enter and be successful in the next level of education. Little emphasis has been placed on students' preparation for life and work. In the last ten to twenty years, employers have become much more vocal, requiring that graduating students at all 
levels be more "work ready." But to be "work ready" does not mean that students need to abandon their emphasis on academic excellence. In fact, employers today require many of the same student qualities for entering workers that are desired or required for entry into institutions of higher learning:

- Understand and be able to use high-level academics (English, mathematics, science, social studies)

- Develop skills in critical thinking and problem solving

- Possess a focus and/or plan for the future

In addition, employers require that workers be able to:

- Interact and communicate openly and clearly with other people

- Function effectively in an organization and in small work teams

- Have a positive work ethic

Many of these attributes can be learned best within the environment of work. And employers are realizing that, to obtain the workforce they seek, they must share their environment, knowledge, experience, and culture for the education of our young people.

Work-based learning is a vital ingredient in the new system. In addition to the attributes listed above, work-based learning can provide motivation by answering the question, "Why do I have to learn this?" It can provide confirmation or denial of initial career choices by answering, "Is this really where I want to be working in my career?" And it can reinforce the importance of positive attitude and functioning effectively in a group or team environment.

Work-based learning should be included several times in the curriculum of the new system. In the ninth and tenth grades, brief experiences (up to twenty hours) at an appropriate worksite and/or employee mentoring help students to understand the environment of work, confirm career decisions, and place context around academic studies. Summer internships (of at least 160 hours) after the junior year in secondary (or part-time employment up to twenty hours per week during the senior year) can facilitate students' application of acquired knowledge and skills to the solution of open-ended, interdisciplinary problems that often require group participation. In some communities, employer-provided work-based learning experiences are not available for secondary students. In these cases, alternatives are created, such as community-based service learning and special project activities provided by nearby community or technical colleges.

In the postsecondary component of the curriculum, students should work a minimum of 400 hours in an "apprenticeship" type capacity (i.e., under close, frequent supervision of experienced workers) to accomplish assigned tasks and to perform useful job functions for employers. This type of experience may allow students to use equipment that is not available in college labs and explore possible after-graduation jobs, and may allow potential employers to evaluate students in consideration of future job offers.

Work-based learning experiences, at all levels, should be structured, goal oriented, and measurable in terms of quantity, quality, and timeliness of job performance. These experiences should be an essential part of the curriculum and assist students in achieving certain of the required standards. Upon successful completion, students should earn credit that is recorded in their transcripts.

\section{Career Guidance and Exploration}

Preparing students to select career pathways and guiding them in plans to enroll in coursework that will lead them to achieve their career goals is essential to helping them meet the challenges of the twenty-first century. Therefore, the new system must have a strong emphasis on career guidance and planning.

Career guidance provides students with the knowledge and skills needed to develop realistic career goals and make appropriate decisions to carry out those goals. Students will begin the career guidance process no later than middle school through a well-planned career exploration program that also involves their parents or guardians. Due to extensive career exploration in the middle grades, students will already have preliminary plans in hand as they enter secondary. This will prepare them for the new secondary-level curriculum, which will be strong in academics but with a career focus. Students will not be tracked and will be encouraged to take high-level courses in order to keep 
their future career options open. Each year they will revisit their career plans with their counselors and parents or guardians to determine whether they are on the career paths of their choice. At that time they will have the opportunity to make changes based on new information they have received and the impact of new experiences they have had.

With focus on planning for their future careers, students will be counseled into work-based learning experiences beginning in the ninth grade. This will allow them to experience more than one career cluster if they are still unsure about their future plans. Ongoing career guidance is necessary to encourage all students to continue their education and training at the postsecondary level. They will be exposed to the concept of lifelong learning throughout their formative years in school.

The purpose of a career guidance and planning program is to impart skills and facilitate learning opportunities in a continuous and integrated manner that ensures that all students have a focus and can relate what they are learning to their career interests. Service learning programs, which involve the entire community, will also assist students as they strive to meet the challenges and demands of the school system and prepare for transitions to options after secondary.

Everyone-including parents, teachers, administrators, and the community — contributes to the guidance process, but the counselor plans and facilitates the process and makes sure that it happens for every student. Students should consider and reconsider career aspirations and plans on a frequent basis through interest and aptitude assessments, employee mentoring, worksite learning, work-related problems that provide context for academic instruction, postsecondary visits and experiences, and counseling sessions that may include parents or other family members.

Thus, the career guidance and planning program in the new system is integrated into the entire curriculum so that all students will have flexible plans that will guide and encourage them to prepare for lifelong learning to support their present and future career goals.

\section{Interdisciplinary Problem Solving}

The new system will move away from technical courses that "teach the task" or simply require memorization. Instead, the new system will include mind-challenging adventures that combine "tools of the trade" (information and skills) within career clusters with problem-based activities that are:

- Interdisciplinary

- Solved by analysis and critical thinking

- Solved by groups as well as individuals

- Open ended, requiring optimization

Most problems in the "real world" are not compartmentalized in only one academic discipline (i.e., math problem, physics problem); rather, involving some complexity, they require the integration and synthesis of information from several disciplines.

Solving complex problems also requires a "critical-thinking" process that may include 1) analysis of the problem, 2 ) breaking it into smaller problems (if needed), 3) amassing resources and/or data, 4) applying information appropriately, 5) determining solutions, 6) integrating the smaller problems into a unified solution, and 7) checking its validity. Learning to think critically is a discipline that must be taught and practiced. Frequently, the ability to solve complex problems requires a group process involving individuals with different areas of expertise and/or experiences.

Many real-world problems are "open ended," i.e., do not have single "best" solutions. Solving them can be approached in several ways, often involving options and trade-offs. Frequently more than one "good" solution exists, and these must be compared on a "cost-versus-benefits" basis to select the one that is optimum.

Because of the interdisciplinary nature of career tasks, technical courses in the new system are the "integrators" that build on the knowledge and skills acquired in the academic disciplines by combining them to solve the real, 
complex problems that confront the global workforce of the new millennium. These new courses will be created through joint efforts by academic teachers, technical teachers, and appropriate employers.

Integration of academic disciplines to solve real-world problems is one of the unique contributions that the new system provides to total school reform.

To adequately measure the value that these integrated courses provide, new high-stakes assessment systems must move from the exclusive use of "pen-and-paper tests" toward interdisciplinary problem-solving exercises.

\section{Secondary Delivery System Based on Career Academies}

In the new system the role of secondary will be to:

- Provide context for academic achievement

- Provide motivation (and desire) to remain in school

- Provide a "level playing field" for students with diverse learning styles

- Provide guidance for career selection and a foundation for career pursuits

- Use career preparation to provide interdisciplinary problem-solving and critical-thinking skills

- Provide a basis for lifelong learning and lifelong earning

This role for education in the new system is clearly not job training as we have provided in the past (i.e., hand skills around a particular machine or procedure), and it cannot be accomplished by technical teachers working in isolation from academic teachers. It will require that students with particular interests in chosen career clusters be grouped together with teachers who are teamed to create and deliver the new curriculum. It will encourage all students to continue their education and training at the postsecondary level. And, for those students who need or want to pursue full-time work after secondary school, the new system will prepare them to enter postsecondary education as parttime students or at some later time in their lives.

A secondary delivery system that has evolved in recent years around this model is the career academy. Career academies are magnet schools or "schools within schools" that provide high standards of academic education within the context of career preparation in particular occupational clusters. Students choose to enter a career academy and may choose to discontinue or change academies if they discover that their first choices are no longer within their interest or aptitude. Students at the same grade level in a career academy are together for their entire four-year secondary experience and are usually taught all four years by the same team of academic and technical teachers.

Students in career academies are encouraged, supported, and challenged to master academic courses at high levels through the careful teaching of courses "in context" for the appropriate career clusters. Career academy students are taught at least one career-related course every term while they are in secondary school. They may elect to take additional courses in the junior and senior years - courses that are provided often by postsecondary institutions for postsecondary credit. In over 350 academies developed by the National Academy Foundation (NAF), over 90 percent of the graduates articulate to postsecondary education and training after secondary graduation.

The new system could encourage transforming area vocational schools (BOCES, ROCS, etc.) into career academies. Area vocational schools are typically eleventh- and twelfth-grade centers that students attend for half days to receive skills training in particular occupations. Academic instruction is usually provided by the "sending school" during the other half day. In this arrangement, it is difficult, if not impossible, to coordinate academics and technical instruction because the required teams of teachers are not working together. In some states and localities, career centers provide both academic and technical instruction in a full-day format. These centers should consider the new curriculum for the full four years of secondary school focused on one or more career clusters. In comprehensive secondary schools, where vocational and academic programs are co-located, the new system would foster the creation of "school-within-a-school" career academies based on career clusters.

Career academies provide the "smaller learning communities" that have proven to be a more effective delivery system in large and medium-sized schools. In small and/or rural schools (with secondary populations below 300 
students), the career academy structure would require significant alteration to address a broader group of careers and clustering of the teaching team.

\section{Community and Technical College Delivery Focused on Full-Time Youth}

Most rewarding occupations require educational preparation beyond secondary; many, however, do not require baccalaureate degrees. Community and technical colleges offer associate degrees (typically two-year courses of study) that provide excellent opportunities to enter internships and well-paying careers in new and changing technical areas. Some graduates with associate degrees may choose to continue their studies to earn baccalaureate degrees at universities.

In recent years, community and technical colleges have experienced a decline of enrollment in their technical programs. Enrollment in engineering-related technologies in particular has fallen, according to the 1997 Digest of Education Statistics. This may be due, in part, to low unemployment rates. However, because enrollment in other areas of higher education is not declining, it is more likely the result of poor recruitment or of misperception by students and their families that these technical programs are "low level" in terms of future earnings or are dead-end in terms of not being transferable to higher education. In some successful Tech Prep consortia with closely articulated secondary and postsecondary curricula, community colleges are receiving more students in technical areas.

In the new system the first two years of postsecondary education are an essential part of the curriculum. This postsecondary role is to provide advanced academics, specialized technical education and training, and facilitation of "apprenticeship-type" work experiences. These two years must be not only a bridge from the secondary experience but also a bridge to other opportunities in higher education and corporate training. For fulfillment of this role, at least three changes are required.

a. The community or technical college must create an effective focus on providing academically based careerpreparation programs for young people who have recently graduated from secondary. This requires that program offerings clearly lead to current, interesting, and new jobs in growing fields, such as photonics, information technology, e-business, and health care. These programs should also connect into advanced studies at four-year colleges.

The postsecondary curriculum for the new system should be designed for full-time students (most of whom will be recent secondary graduates) who plan to complete the two years of study and receive associate degrees. This is very different from programs that presently exist at most community and technical colleges - programs that focus on serving older adults (many with poor backgrounds in academics) who typically return to college for a few "job-training" courses.

Community and technical colleges must also recruit greater numbers of recent secondary graduates into these new programs. This will require more effective public information programs to convince young people, their parents, and secondary counselors that technical education is the gateway to rewarding jobs and higher education. This message can - and should - be conveyed by counselors, employers, universities, and former students.

b. Contextual teaching should be adopted by faculties at community and technical colleges to enable more students to successfully achieve advanced levels of math and science. This improved approach to effective learning is not being practiced at most colleges. Faculty members must be introduced to contextual teaching strategies and given the incentive to change to this form of pedagogy. In fact, the development of improved teaching skills for all faculty members should be enhanced and extended.

c. Community and technical college partnerships with businesses (employers) must be created to define and support student apprenticeships, program quality and relevance, and public relations to encourage more students to choose career preparation.

Use of employer advisory committees in most colleges is weak-limited to infrequent meetings, provision of advice for which there is little accountability for faculty response, and provision of support that consists of donations of student scholarships and outdated equipment. Business partnerships required for the new system engage and empower committees of "second-level" managers who work with secondary and postsecondary 
faculty and administrators. The partnerships must create and sustain educational programs to prepare students for rewarding careers that will begin four to six years in the future (when the students will become employees) and must design and conduct the worksite learning experiences discussed earlier.

\section{The Photonics Curriculum Model for the "New System"}

The following $4+2$ (secondary/postsecondary) curriculum model is appropriate for use in the "New System" (Figure 2). Course materials for the technical specialty courses are being developed by CORD and the University of Connecticut under a Scientific and Technological Education in Photonics (STEP) grant from the National Science Foundation, ${ }^{5}$ using the National Photonics Skills Standard for Technicians developed by CORD. ${ }^{6}$

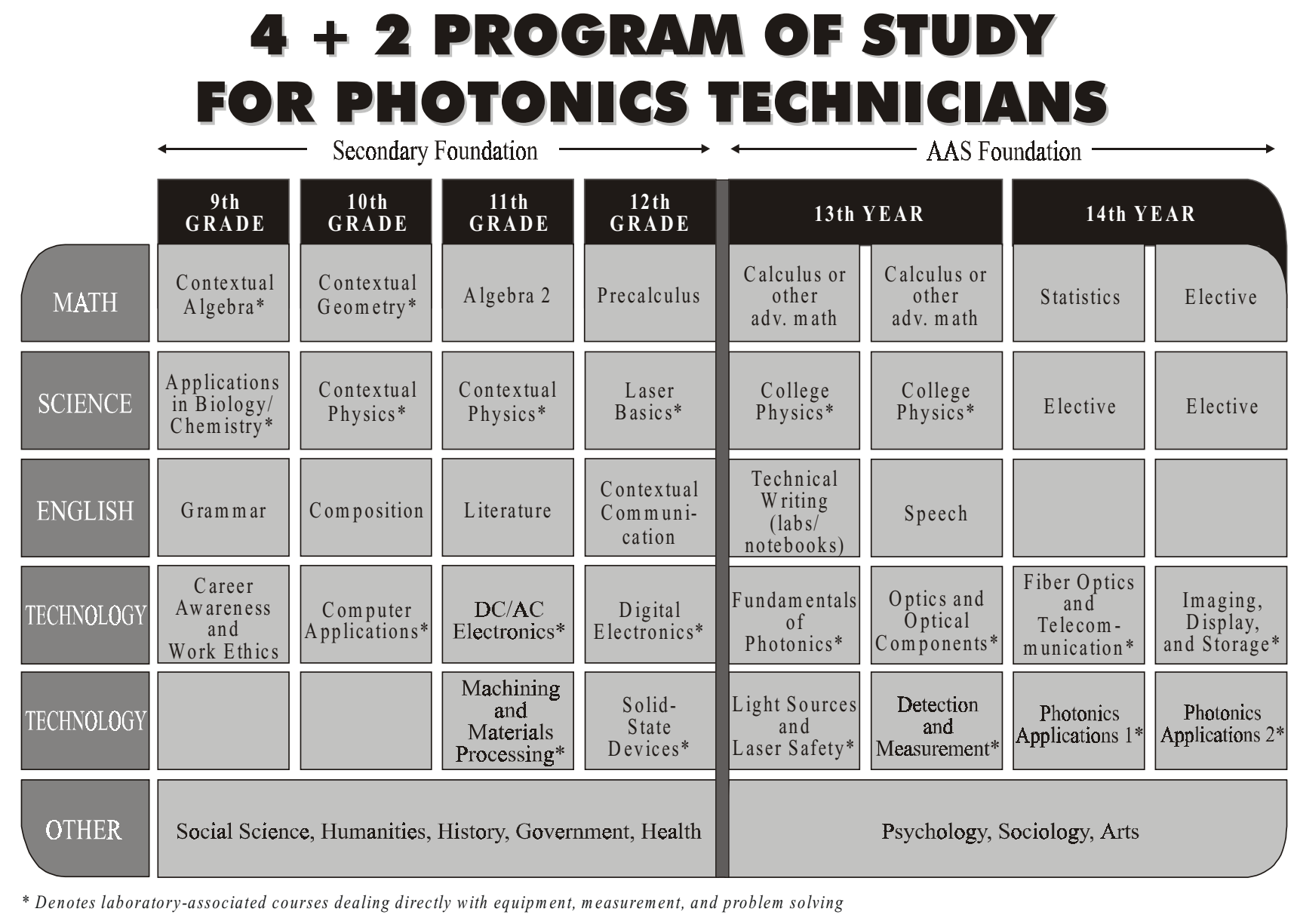

Figure 2. $4+2$ Program of study for photonics technicians

${ }^{5}$ See a description of the project at www.cord.org/STEPII.
${ }^{6}$ CORD. National Photonics Skills Standard for Technicians. Waco, TX: CORD, 1995. 